\title{
Erratum to: Traveling-wave Thomson scattering and optical undulators for high-yield EUV and X-ray sources
}

\author{
A.D. Debus - M. Bussmann • M. Siebold • A. Jochmann • \\ U. Schramm • T.E. Cowan · R. Sauerbrey
}

Received: 26 February 2010 / Published online: 26 August 2010

(C) Springer-Verlag 2010

Erratum to: Appl Phys B (2010) 100: 61-76

DOI 10.1007/s00340-010-3990-1

On p. 72 in Table 3 the value for the scattered photon energy $\hbar \omega_{\text {sc }}$ at $1.8 \mathrm{MeV}$ is not correct. The correct value is $3.5 \mathrm{MeV}$.

The online version of the original article can be found under doi:10.1007/s00340-010-3990-1.

A.D. Debus $(\varangle) \cdot$ M. Bussmann · M. Siebold · A. Jochmann ·

U. Schramm · T.E. Cowan · R. Sauerbrey

Forschungszentrum Dresden-Rossendorf, Institute for Radiation

Physics, 01328 Dresden, Germany

e-mail: a.debus@fzd.de 